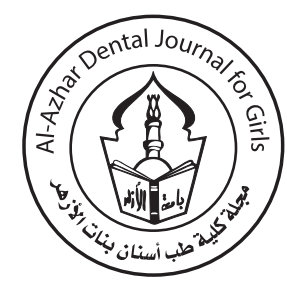

\title{
In Vitro Remineralizing Effect of Some Herbals on Initial Enamel Carious Lesions
}

\author{
Nasr M. Attia ${ }^{1 *}$, Rasha I. Ramadan ${ }^{1}$
}

Codex : 19/21.04

azhardentj@azhar.edu.eg

http://adjg.journals.ekb.eg

DOI: $10.21608 /$ adjg.2021.29117.1253

Pediatric Dentistry \& Orthodontics ( Pediatric Dentistry, Orthodontics)

\section{KEYWORDS}

Remineralization, Herbals, Initial enamel carious lesions

\begin{abstract}
Purpose: As the goal of modern dentistry is the non-invasive management of non-cavitated caries lesions and the growing interest in the field of phytotherapeutics by the medicinal use of their plant extracts, this study was conducted to evaluate the remineralizing potential of some herbals (tea tree, grape seed, and ginger) in comparison with fluoridated toothpaste on initial enamel carious lesions. Materials and Methods: Forty human enamel samples were classified into four groups. Ten samples for each group were used in this in vitro recycling study with the following treatments which applied three times a day: 1) tea tree oil, 2) grape seed oil, 3) ginger oil, and 4) sodium fluoride toothpaste. Treatment regimens of demineralization and remineralization cycle were applied for 21 days. The baseline and post-treatment data were assessed by digital radiographs of the mineral density of WSLs based on subtraction concept. Data were statistically analyzed by ANOVA test with Bonferroni significant difference test. Results: There was no statistically significant difference between different study groups (fluoride, tea tree, grape seed, and ginger) along consequent follow up periods. While, after repeated measure analysis, there was a statistically significant difference regarding all the study groups respectively $(0.12(0.00), 0.22(0.01), 0.25(0.02), 0.12$ (0.00). The post hoc test for each study group showed also a significant decrease in mineral density along different follow-up periods $(\mathrm{P} \leq 0.05)$. Conclusion: There was no statistically significant difference between different study groups on remineralization of initial caries lesion.
\end{abstract}

\section{INTRODUCTION}

A white spot lesion (WSL) is demineralization of enamel leading to subsurface porosity and it is considered the early sign of tooth decay. The subsurface porosity is mainly occurred due to imbalance between demineralization and remineralization processes. The concept of minimal invasive dentistry recommended treatment of incipient

1. Lecturer at Department of Pedodontics and Dental Public Health, Faculty of Dentistry, Mansoura University, Egypt.

* Corresponding author email: nasrattia@mans.edu.eg 
carious lesion by remineralizing agents. So, many forms of fluoride as dentifrices, mouthwashes, gel and varnish was used for management of incipient caries ${ }^{(1)}$.

At the atomic level; the demineralization process initiates on the crystalline surfaces of the enamel and progresses into a cavity by time. It starts by dissolving nearby half of the minerals into the enamel, leaving a roof of 2-50 $\mu \mathrm{m}$ of mineralized surface. Clinically, it will appear chalky white and softened ${ }^{(2)}$.

Arresting of the caries process at that white spot lesion stage with non-invasive technique is the ultimate goal. With progresses of the lesion, cavitation will occur, which necessitates an operative intervention. The tooth is exposed to unlimited cycles of demineralization and remineralization. The produced acid diffuses into the tooth leading to outflow of calcium and phosphate from the enamel. This mineral loss leads to cavitation. Early intervention to management of the caries by preventive strategy is more preferred than a curative approach ${ }^{(3,4)}$.

There is a strong scientific evidence supports the using of fluoride for caries prevention; in spite of that nowadays there are many restrictions arise for its use such as anti-fluoridation gangs and parents apprehension about use of fluoride for their children. In conjunction to the growth of drug resistance, the use of antimicrobial agents has many adverse effects on the digestive system ${ }^{(3)}$

In developing countries, due to the financial situation, the growing attention to the use of herbal extracts as grape seeds, cinnamon oil, tea tree oil and garlic extract as phytotherapy has revealed potent antimicrobial and preventive effects on artificial antibiotics due to their biocompatibility and efficiency ${ }^{(5-10)}$.

Tea tree oil (TTO) is an essential oil, consisting of volatile aromatic hydrocarbons. It contains antimicrobial constituents which cause leakage of the membrane integrity and inhibiting the respiration of the bacterial cells. In addition to its ability in making the bacterial cells more susceptible to sodium chloride through leaking of light absorbing materials ${ }^{(11,12)}$.

Several researches performed on TTO and supported its antibacterial properties. Two Studies proved the reluctant efficacy of TTO on S. mu$\operatorname{tans}{ }^{(13,14)}$. Additionally, another study explored a significant reduction in the count of salivary S. mutans using soaked toothbrushes with $0.2 \%$ TTO for half a day compared to $0.12 \%$ chlorhexidine (CHX) mouthwash ${ }^{(15)}$.

Grapes seeds extract (GSE) is consist mainly of proanthocyanidins (PAs), it considered strong antioxidants, it also have vasodilatory effects, antiseptic and anti-carcinogenic effects. PAs contain a variety of flavonoids which act as a scavenger that increase the calcium absorption. It is also increase the stability of collagen matrices through its polyphenol components ${ }^{(16)}$

GSE facilitates remineralization of demineralized dentin, by both its $\mathrm{pH}$ and concentration, which mainly arises from its high polyphenolic content ${ }^{(17)}$. Also, in vitro study, GSE enhances the process of remineralization of artificial caries in primary teeth. Therefore, it can be considered an effective natural agent for non-invasive carious lesion therapy ${ }^{(18)}$.

Ginger rhizome is a natural herbal with noticeable antimicrobial properties, it is safe without any toxic effect as it is FDA approved. In addition to the antimicrobial properties, its antifungal effects on oral cavity pathogens was proved ${ }^{(19,20)}$. In spite of that, there are insufficient studies which assess the remineralizing efficacy of ginger on incipient enamel carious lesions.

Therefore, there is rising need for efficient noninvasive systems in remineralizing incipient enamel carious lesions. This study was performed to assess the remineralizing ability of some herbals (tea tree oil, grapes seeds oil, and ginger) in comparison with fluoride on incipient enamel carious lesions. 


\section{MATERIALS AND METHODS}

This study had been performed after approval of Research Ethics Committee of Faculty of Dentistry under this code number [29020418]

Forty samples were calculated, demonstrating a $30 \%$ decreases in the severity of WSLs between the control and experimental groups, with power of $86 \%$ and level of significance as $95 \%{ }^{(21)}$.

Twenty fresh human sound extracted premolars were selected. Extraction of the teeth was mainly due to orthodontics needs or periodontitis. The extraction was done after taking informed consent from patients. The buccal and palatal or lingual surfaces with any visible signs of demineralization such as caries, white or brown spot lesion, cracks, erosion, abrasion or any other developmental defects were excluded from the study ${ }^{(22)}$.

\section{Samples cleaning and storage}

The selected teeth were thoroughly cleaned with distilled water using a soft toothbrush to remove plaque, blood, and remaining tissue tags, then they were preserved in a solution of $0.1 \%$ thymol till use ${ }^{(23)}$. Infection control measures were undertaken prior to manipulate the extracted teeth. All the collected teeth were immersed in Glutaraldehyde solution $2 \%$ for one day, then the teeth were washed using distilled water prior to their use. Personal protective barrier including gloves, mask, protective eyewear and white coat were used during sample preparation.

\section{Sample preparation}

The crown of each tooth was longitudinally sectioned mesiodistally using a high-speed diamond tipped disc (Galaxy ${ }^{\mathrm{TM}}$ Diamond Discs: Double sided perforated) to obtain buccal, and palatal or lingual sections creating 40 samples. Each section will be embedded in self-cure acrylic resin with the buccal and palatal or the lingual surface faced upward.

\section{Lesion creation}

Lactic acid $\left(\mathrm{C}_{3} \mathrm{H}_{6} \mathrm{O}_{3}\right)$ was used as a demineralizing solution. It contains Assay 88\%, sulphated ash $0.1 \%$, Iron $0.001 \%$, Chloride $0.02 \%$, sulphate $0.02 \%$, lead $0.001 \%$, Arsenic $0.0003 \%$, Calcium $0.02 \%$ and mercury $0.0001 \%$. It is adjusted to $\mathrm{PH}$ 5 using $\mathrm{NaOH}^{(24)}$. Two layers of acid resistant nail varnish were applied to each sample, leaving a window of $3 \times 3 \mathrm{~mm}$ of enamel exposed at the center of the sample. These established windows seen at the center of the tooth surface was demineralized by incubating in $10 \mathrm{ml}$ lactic acid for 3 days at $37^{\circ} \mathrm{C}$ without stirring to create the artificial white spot lesions (WSLs), the $\mathrm{pH}$ meter was used to detect the $\mathrm{pH}$ value daily. After that period, all samples were removed from the solution and then washed for 5 minutes under tap water, then washed again under distilled water for $30 \mathrm{~s}$ and dried with air spray free of oil to be visualized for their chalky white appearance $^{(23)}$.

\section{Treatment regimen and pH cycling}

After inducing the incipient lesions, samples were randomly divided into four equal groups using block randomization technique $(\mathrm{n}=10)^{(25)}$. Three groups are experimental groups (tea tree oil group, grape seed oil group, and ginger oil group) and one group for the positive control group (fluoride group).

Therapeutic agents were applied three times daily with an applicator for $1 \mathrm{~min}$. the pure extract oil of these herbals was used ${ }^{(26)}$. The pure herbal oils were ready-made at Al-Badawia Company for extraction of vegetable oils. The three herbal oils were acidic $(\mathrm{pH}=5)$ and their viscosity were 8 times more than water. NaF toothpaste had been used as a positive control group, consisted of $1450 \mathrm{mg} / \mathrm{kg}$ fluoride.

Artificial saliva was prepared at the Pharmaceutics Department, Faculty of Pharmacy, according to the modified method of Macknight Hane and Whitford (1992) ${ }^{(27)}$.The artificial saliva was prepared 
without sorbitol as it increase the viscosity of normal saliva when stirred with $\mathrm{Na} \mathrm{CMC}^{(28)}$. By mixing two grams of methylparaben with $800 \mathrm{ml}$ of distilled water under magnetic stirring. After that, 10 $\mathrm{g}$ of $\mathrm{Na} \mathrm{CMC}$ was sprinkled over the surface of the obtained dispersion to allow polymer soaking overnight. Then, the remaining components were dissolved in the following order; $0.625 \mathrm{~g}$ of $\mathrm{KCl}, 0.059$ $\mathrm{g}$ of $\mathrm{MgCl}_{2} .6 \mathrm{H}_{2} \mathrm{O}, 0.166 \mathrm{~g}$ of $\mathrm{CaCl}_{2} .2 \mathrm{H}_{2} \mathrm{O}, 0.804 \mathrm{~g}$ of $\mathrm{K}_{2} \mathrm{HPO}_{4}$ and $0.326 \mathrm{~g}$ of $\mathrm{KH}_{2} \mathrm{PO}_{4}$ under magnetic stirring. The volume was completed to $1 \mathrm{~L}$ using distilled water and magnetically stirred for about 24 hours to ensure solubility and homogeneity of all components. $\mathrm{KOH}$ was used to adjust the $\mathrm{pH}$ to 7 and avoid any precipitation during the process. The saliva was changed every day ${ }^{(29)}$.

In the experiment, the application was followed by the $\mathrm{pH}$ cycle model for 21 days (table 1). Daily, each group samples were solely dipped for 3 hours in $7 \mathrm{ml}$ of fresh lactic acid that mimics the acid challenges of the oral cavity and then stored in $20 \mathrm{ml}$ of fresh artificial saliva that mimics the remineralizing oral fluid for 21 hours ${ }^{(24)}$.

Table (1): The cycling model of PH.

\begin{tabular}{|l|l|}
\hline Time & Application \\
\hline $\mathbf{8}-\mathbf{9}$ & Lactic acid \\
\hline 9- 9:01 & Therapeutic agents \\
\hline 9:01 - 13 & Artificial saliva \\
\hline 13-14 & Lactic acid \\
\hline 14- 14:01 & Therapeutic agents \\
\hline 14:01 - 19 & Artificial saliva \\
\hline 19- 20 & Lactic acid \\
\hline $\mathbf{2 0 - 2 0 : 0 1}$ & Therapeutic agents \\
\hline 20:01 - 8 & Artificial saliva \\
\hline
\end{tabular}

All groups were then exposed to a secondary demineralization attack same as the demineralizing solution used for initial demineralization for 72 hours in the incubator without stirring. Then all samples were removed from the solution and washed with water ${ }^{(23)}$.

\section{Assessment of mineralization}

Forty teeth were examined using $\mathrm{x}$-rays recorded on HD digital sensors (Vatech, CMOS detector, $14.9 \mu \mathrm{m}$ pixel size, $33.78 \mathrm{Ip} / \mathrm{mm}$ theoretical resolution), and exposed for four impulses from $\mathrm{x}$-ray machine at the same distance between cone and sensor. For each sample standardized digital periapical radiographic shots were taken at four different intervals; at the baseline, after WSLs creation, after therapeutic agents application, and lastly, after the second demineralization cycle. A custom made device was used to standardize the projection geometry at subsequent radiographic shots. Teeth were positioned on a protective sleeve on the sensor, the facial surface facing the $\mathrm{x}$-ray tube. These digital radiographs were analyzed for mean mineral density of the carious lesions by gray scale (256 levels) using histogram tool in Adobe Photoshop A 7 program based on the subtraction concept ${ }^{(30)}$.

Both assessors who perform the application of therapeutic agents and radiographic assessment were blinded alternatively.

\section{Statistical analysis:}

Data were gathered, computed and then statistically analyzed using the Social Sciences Statistical Package (SPSS PC Version 20.0).

\section{RESULTS}

The effect of fluoride and some herbal extracts on remineralization of incipient carious lesions was assessed, analyzed and tabulated (table 2, and 3 ) to illustrate the following results:-

Clinical and radiographic pictures among different study groups along base line and consequent follow up periods were showed in table 2. These digital radiographs were subsequently analyzed for mean mineral density of the carious lesions by Adobe Photoshop A 7 program based on the subtraction concept. 
Table (2):Clinical and radiographic pictures among different study groups along consequent follow up periods.

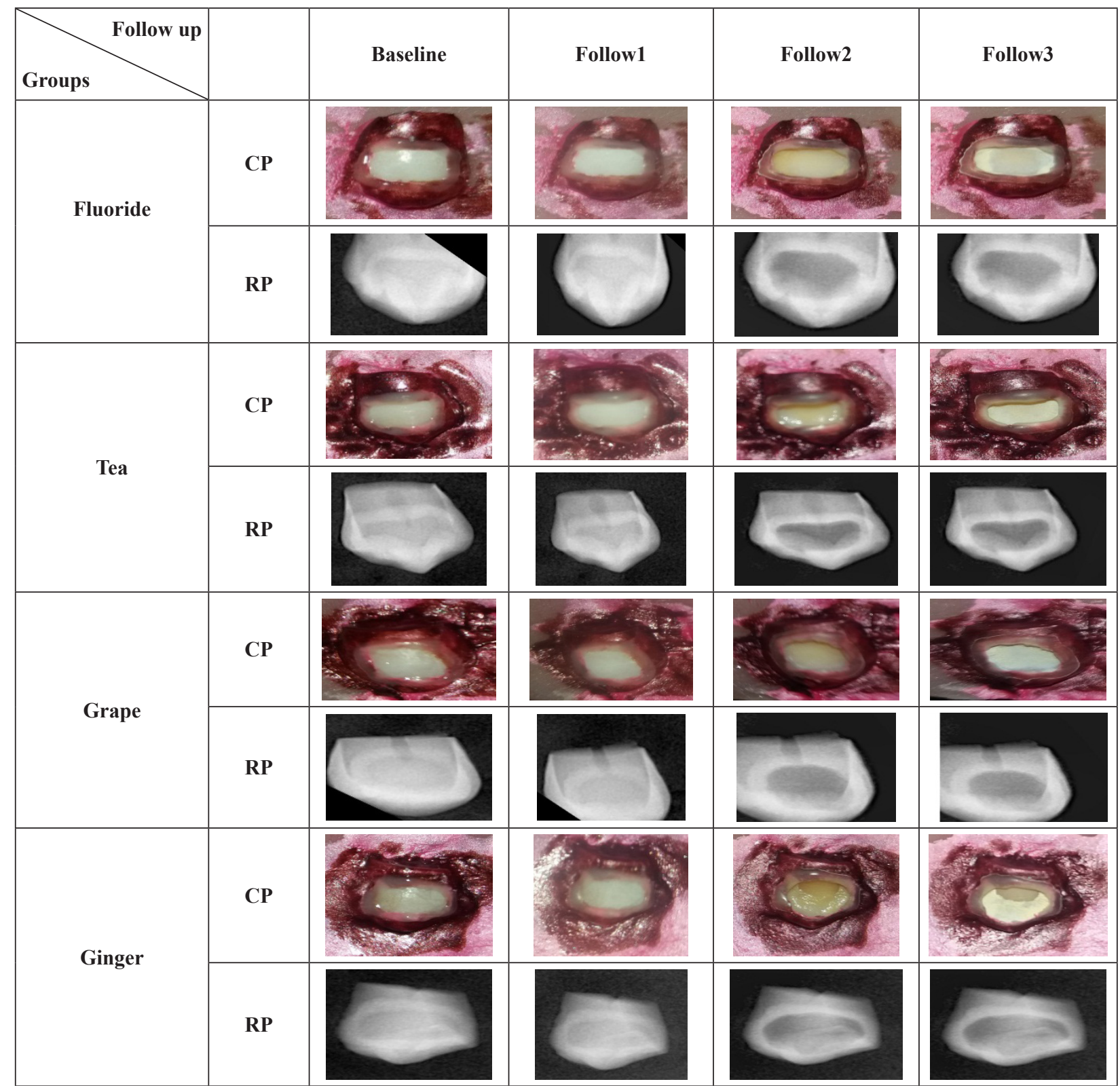

$C P=$ clinical picture, $R P=$ radiographic picture

Follow $1=$ first demineralization, Follow $2=p H$ cycling, Follow $3=$ second demineralization

The mean mineral density among different study groups along base line and consequent follow up periods were showed at table 3. By using One Way ANOVA test (F), there was no statistically significant difference between different study groups (fluoride, tea tree oil, grape oil, and ginger oil) along consequent follow up periods ( $\mathrm{P} \geq 0.05)$.
By using results of Wilks' Lambda test after repeated measure analysis, there was a statistically significant difference regarding all the study groups respectively (0.12 (0.00), $0.22(0.01), 0.25(0.02)$, $0.12(0.00)$. The post hoc test for each study group showed also a significant decrease in mineral density along different follow-up periods $(\mathrm{P} \leq 0.05)$. 
However, the study groups may be ordered from the least affected (decreased mineral density) to the largest in this manner: tea tree followed by ginger followed by grape and finally fluoride based on their mean difference between first and second demineralization cycles.

Table (3): Mean mineral density among different study groups along consequent follow up periods

\begin{tabular}{|c|c|c|c|c|c|}
\hline Groups & $\begin{array}{c}\text { Baseline } \\
\text { mean } \pm \text { SD }\end{array}$ & $\begin{array}{c}\text { Follow1 } \\
\text { (first demineralization) } \\
\text { mean } \pm \text { SD }\end{array}$ & $\begin{array}{c}\text { Follow2 } \\
\text { (pH cycling) } \\
\text { mean } \pm \text { SD }\end{array}$ & $\begin{array}{c}\text { Follow3 } \\
\text { (second demineralization) } \\
\text { mean } \pm \text { SD }\end{array}$ & $\begin{array}{c}\text { Wilks, } \\
\text { lambda } \\
\text { (P value) }\end{array}$ \\
\hline Fluoride & $193.1 \pm 16.93$ & $181.9 \pm 17.46$ & $143.1 \pm 30.62$ & $141.9 \pm 30.99$ & $\begin{array}{c}0.12 \\
(\mathbf{0 . 0 0 )}\end{array}$ \\
\hline $\begin{array}{c}\text { MD } \\
\text { P value }\end{array}$ & & $\begin{array}{c}11.26 \\
\text { P1=0.04 }\end{array}$ & $\begin{array}{c}38.74 \\
\mathbf{P} 2=\mathbf{0 . 0 1}\end{array}$ & $\begin{array}{c}1.17 \\
\mathbf{P 3}=\mathbf{0 . 0 2}\end{array}$ & \\
\hline Tea & $191.1 \pm 17.68$ & $179.6 \pm 15.13$ & $152.8 \pm 24.45$ & $149.8 \pm 25.67$ & $\begin{array}{c}0.22 \\
(\mathbf{0 . 0 1})\end{array}$ \\
\hline $\begin{array}{c}\text { MD } \\
\text { P value }\end{array}$ & & $\begin{array}{c}11.48 \\
\mathbf{P 1}=\mathbf{0 . 0 2}\end{array}$ & $\begin{array}{c}26.77 \\
\mathbf{P} 2=\mathbf{0 . 0 5}\end{array}$ & $\begin{array}{c}2.98 \\
\text { P3 }=0.04\end{array}$ & \\
\hline Grape & $194.1 \pm 19.36$ & $188.7 \pm 18.58$ & $154.8 \pm 23.94$ & $151.6 \pm 24.06$ & $\begin{array}{c}0.25 \\
(\mathbf{0 . 0 2})\end{array}$ \\
\hline $\begin{array}{c}\text { MD } \\
\text { P value }\end{array}$ & & $\begin{array}{c}5.46 \\
\mathbf{P 1}=\mathbf{0 . 0 4}\end{array}$ & $\begin{array}{c}33.84 \\
\mathbf{P} 2=0.02\end{array}$ & $\begin{array}{c}3.26 \\
\mathbf{P 3}=\mathbf{0 . 0 3}\end{array}$ & \\
\hline Ginger & $191.1 \pm 14.88$ & $178.5 \pm 11.76$ & $147.7 \pm 15.44$ & $142.7 \pm 16.15$ & $\begin{array}{c}0.12 \\
(\mathbf{0 . 0 0 )}\end{array}$ \\
\hline $\begin{array}{c}\text { MD } \\
\text { P value }\end{array}$ & & $\begin{array}{c}12.48 \\
\mathbf{P 1}=\mathbf{0 . 0 4}\end{array}$ & $\begin{array}{c}30.75 \\
\mathbf{P} 2=\mathbf{0 . 0 0}\end{array}$ & $\begin{array}{c}4.97 \\
\mathbf{P 3}=\mathbf{0 . 0 3}\end{array}$ & \\
\hline $\begin{array}{c}\mathbf{F} \\
\text { (P value) }\end{array}$ & $\begin{array}{c}0.08 \\
(0.97)\end{array}$ & $\begin{array}{c}0.83 \\
(0.49)\end{array}$ & $\begin{array}{c}0.47 \\
(0.70)\end{array}$ & $\begin{array}{c}0.39 \\
(0.76)\end{array}$ & \\
\hline
\end{tabular}

$P$ value $\leq 0.05$ level, $M D=$ mean difference, $S D=$ standard deviation, $F=$ One Way ANOVA test

$P 1=$ between baseline and follow $1, P 2=$ between follow 1 and $2, P 3=$ between follow 2 and 3

\section{DISCUSSION}

For thousands of years, the natural products were considered a promising therapeutics especially for oral conditions as dental caries $^{(31-33)}$. So, many preventive interventions were conducted to preserve the tooth structures (31). Among them, fluoride, which was considered the gold standars for subsequent interventions. NaF toothpaste was used as positive control to assess the remineralizing efficacy of other herbal agents.

The assessing of changes within a remineralizing lesion is difficult because of changes in the volume of minerals, mechanical properties and histology of the tooth structure. Unfortunately, it could not be applied intra-orally as it will destruct the tooth structure. The assessment of remineralizing lesions clinically, by detecting the appearance and texture of the surface are not sufficient to assess and understand the process of remineralization. From this point of view, this in-vetro study was performed;The standardized digital radiographs were analyzed based on the subtraction concept as it is simple, easy, quick, and nondestructive method in assessing changes in minerals density. Additionaly, it provides repeated standardized evaluations of the same samples at different times and could be used intraorally ${ }^{(34)}$. 
A $\mathrm{pH}$ cycling was performed in this study to simulate the remineralizing and demineralizing oral fluid conditions. The three hours duration of demineralization is similar to the one day acid challenge intra-orally ${ }^{(23)}$. Despite individual differences, as the oral cavity environment may be affected by different dietary habits and accumulated plaque, this demineralized time was used to standardize the conditions in the study ${ }^{(35)}$.

The net results of this study revealed no significant difference between the studied groups (tea tree, grape seed, ginger, and sodium fluoride $1450 \mathrm{ppm}$ ) regarding changing in the mean mineral density.

This shall be consistent with the results of this study ${ }^{(36)}$, which assessed the efficacy of grape seed extract in minimizing the cariogenic potential of enamel caries. Their result reported that both fluoride and grape seed extract behaved in the same way in preventing demineralization, additionally it creates insoluble collagen complexes on the surface layer of the lesion which accelerates minerals deposition and crossliking of proteins ${ }^{(32,37)}$.

Collagen type I was discovered in enamel in another study ${ }^{(38)}$; which could be engaged in enamel mineralization. In relation to this; grape seed extract may improve the ultimate tensile strength of demineralized enamel as shown before in dentin.

A study was conducted $2016^{(24)}$, found that there is no significant difference between ginger and sodium fluoride toothpaste on remineralization of initial enamel lesions which assessed using qualitative light-induced fluorescence technique. The similar remineralizing effect of ginger is probably due to the excess quantity of fluoride within ginger (79 mg/kg fluoride).

Also, however, the effect of TTO on remineralization of initial caries not established yet as regarding to our knowledge, some authors reported that tee tree oil could be utilized as a cavity disinfectant that reduce the risk of secondary caries formation which mimic fluoride effect ${ }^{(39)}$.
Unfortunately, our results showed a significant decrease in the mean mineral density after the first and second demineralization cycles in all studied groups and this could be attributed to the acidic $\mathrm{pH}$, the used formula and the viscosity of herbal oils groups, in addition to the concentration of fluoride group.

As for tea tree, grape seed extract and ginger; the $\mathrm{pH}$ of the three herbal oils were acidic $(\mathrm{pH}=5)$ which may counteracts the remineralizing ability of the herbal agents which subsequently lead to decrease of the mean mineral density of the teeth

We used the pure extract oil form which may no longer retained on the teeth as varnish form due to its high molecular weight and size, high density $(1.025 \mathrm{~g} / \mathrm{cm} 3)$ and high viscosity (8 times more than water) which minimize its penetration into the subsurface layer, in addition to increase the surface tension ${ }^{(40)}$. This is similar to an established study performed $2015^{(41)}$, which found that the antimicrobial efficacy of fluoride and herbal mouth washes on salivary streptococcus mutans counts was similiar While oil extraction did not have any significant benefits in decreasing the bacterial counts.

As no evidence until now supports that the fluoride varnish is better than toothpaste in caries reduction ${ }^{(42,43)}$, the used fluoride formula in this study was the toothpaste but, it could not be retained on the teeth surface as varnish form. Fluoride varnish acts as a reservoir that is retained and release fluoride for long periods of time. The lower concentration of the used fluoride toothpaste (1450 ppm), may be attributed to its insignificant effect on inhibition of demineralization of initial caries as proved by this study ${ }^{(44)}$, which detected that the use of $5000 \mathrm{ppm}$ fluoridated toothpaste, two times daily in patients with root caries significantly increases its hardness when compared with ordinary $1,350 \mathrm{ppm}$ fluoridated toothpaste. 


\section{CONCLUSION}

This study revealed no statistically significant difference among pure herbal extract oils used and sodium fluoride toothpaste. Additionally, all of them had no effect on prevention of initial enamel carious lesions. Taking into considerations that the used form of herbal agents has poor retention properties to the teeth surface and using of these herbal agents in varnish form should be evaluated. So, we suggest further investigations of the potential benefits of herbal varnishes for enhancing remineralization.

\section{REFERENCES}

1. Bassant A, Eiman S, Abbas R. Treatment of various degrees of white spot lesions using resin infiltration-in vitro study. Prog Orthod. 2018; 19: 27.

2. Horuztepe SA, Baseren M .Effect of resin infiltration on the color and micro hardness of bleached white-spot lesions in bovine enamel (an in vitro study.J Esthet Restor Dent. 2017; 29:378-85.

3. Nebu Philip. State of the Art Enamel Remineralization Systems: The Next Frontier in Caries Management. Caries Res. 2019 ; 53: 284-95.

4. Shahnawaz K, Upasana R, Stephin J, Anand N, Teena D. Is there evidence for Novamin application in remineralization?: A Systematic review .J Oral Biol Craniofac Res. 2020 ; 10: 87-92.

5. Hammer KA, Dry L, Jhonson M, Michalak EM, Carson CF, Riley TV. Susceptibility of oral bacteria to Melaleuca alternifolia (tea tree) oil in vitro. Oral Microbiol Immunol. 2003; 18:389-92.

6. Oussalah M, Caillet S, Saucier L, Lacroix M. Antimicrobial effects of selected plant essential oils on the growth of a Pseudomonas putida strain isolated from meat. Meat Sci. 2006; 73:236-44.

7. Sharififar F, Moshafi MH, Mansouri SH, Khodashenas M, Khoshnoodi M. In vitro evaluation of antibacterial and antioxidant activities of the essential oil and methanol extract of endemic Zataria multiflora Boiss. Food Control. 2007; 7:800-5.

8. Prabhakar AR, Ahuja V, Bassappa N. Effect of curry leaves, garlic and tea tree oil on Streptococcus mutans and lactobacilli in children: A clinical and microbiological study. Bras Res Ped Dent Int Clin. 2009; 9:259-63.
9. Dalirsani Z, Aghazadeh M, Adibpour M, Amirchaghm M, Pakfetrat A, Mosannen MP, et al. In vitro comparison of the antimicrobial activity of ten herbal extracts against Streptococcus mutans with chlorhexidine. J Appl Sci. 2011; 11:878-82.

10. Palombo EA. Traditional medicinal plant extracts and natural products with activity against oral bacteria: potential application in the prevention and treatment of oral diseases. Evid Based Complement Alternat Med. 2011; 2011: 680354.

11. Rathina $\mathrm{S}$ and Geetha R. Action of tea tree oil and cinnamon leaf oil against oral pathogens.Asian J Pharm Clin Res. 2015; 8, : 80-1

12. Dagli N, Dagli R, Mahmoud R, Baroudi K. Essential oils, their therapeutic properties, and implication in dentistry: A review. J Int Soc Prevent \& Communit Dent. 2015; 5 : $335-40$.

13. Groppo FC, Ramacciato JC, Simões RP, Flório FM, Sartoratto A. Antimicrobial activity of garlic, tea tree oil, and chlorhexidine against oral microorganisms. Int Dent J. 2002;52:433-7.

14. Takarada K, Kimizuka R, Takahashi N, Honma K, Okuda $\mathrm{K}$, Kato T. A comparison of the antibacterial efficacies of essential oils against oral pathogens. Oral Microbiol Immunol. 2004; 19:61-4.

15. Chandrdas D, Jayakumar HL, Chandra M. Evaluation of antimicrobial efficacy of garlic, tea tree oil, cetylpyridinium chloride, chlorhexidine, and ultraviolet sanitizing device in the decontamination of toothbrush. Indian J Dent. 2014; 5:183-9.

16. Nicole MD and Brandi NC. Prevention of Dental Caries by Grape Seed Extract Supplementation: A Systematic Review. Nutr Health.2020 ;26:43-52.

17. Cheng Tang, Ming Fang, Rui-ruiLiu, QiDou, ZhiguoChai, Yu-hongXiao, et al. The role of grape seed extract in the remineralization of demineralized dentine: Micromorphological and physical analyses. Archives of Oral Biology 2013;58: 1769- 76

18. Mahkameh M, Solmauz E, Majid B,Abbas D, Mohammad J. Remineralization of Artificial Caries in Primary Teeth by Grape Seed Extract: An In Vitro Study. JODDD. 2013; 7: 206-10

19. Mathai K, Anand S, Aravind A, Dinatius P, Krishnan AV, Mathai M. Antimicrobial Effect of Ginger, Garlic, Honey, and Lemon Extracts on Streptococcus mutans. J Contemp Dent Pract. 2017;18:1004-8. 
20. Mao QQ, Xu XY, Cao SY, et al. Bioactive Compounds and Bioactivities of Ginger (Zingiber officinale Roscoe). Foods. 2019;8(6):185.

21. Eldridge SM, Ashby D, Kerry S. Sample size for cluster randomized trials: effect of coefficient of variation of cluster size and analysis method. Int J Epidemiol 2006:35: 1292-300.

22. Arslan S, Lipski L, Dubbs K, Elmali F, Ozer F. Effects of different resin sealing therapies on nano leakage within artificial non-cavitated enamel lesions. Dent Mater J. 2018;37:981-7.

23. Hua F, Yan J, Zhao S. In vitro remineralization of enamel white spot lesions with a carrier-based amorphous calcium phosphate delivery system. Clin Oral Invest. 2020;24: 2079-89.

24. Gulcin G, Funda Y, Dilek T, George K, Bruce R, Osman H. Effectiveness of some herbals on initial enamel caries lesion. Asian Pac J Tro Biomed. 2016;6:846-50.

25. Suresh K. An overview of randomization techniques: An unbiased assessment of outcome in clinical research. J Hum Reprod Sci. 2011;4 : 8-11.

26. Buhner SH. Herbal antibiotics, natural alternatives for treating drug-resistant bacteria. 2nd ed. North Adams: Storey Publishing; 2012.

27. Macknight-Hane C and Whitford GM. Fluoride release from three glass ionomer materials and the effects of varnishing with or without finishing. Caries Res 1992; 26: 345-50.

28. Lysik D, Niemirowicz-Laskowska K, Bucki R, Tokajuk G, Mystkowska J. Artificial Saliva: Challenges and Future Perspectives for the Treatment of Xerostomia. Int J Mol Sci. 2019;20:3199.

29. Amaechi BT and Higham SM. In vitro remineralization of eroded enamel lesions by saliva. J Dent .2001, 29:371-6.

30. Aghmasheh F, Bardal R, Reihani Z, Moghaddam M, Taban S, Fallahzadeh F. Comparative study of the effect of direct and indirect digital radiography on the assessment of proximal caries. Indian J Dentistry 2013; 4:83-7.

31. Cruz Martínez C, Diaz Gómez M, Oh MS. Use of traditional herbal medicine as an alternative in dental treatment in Mexican dentistry: a review. Pharm Biol. 2017;55:1992-8.

32. Jawale KD, Kamat SB, Patil JA, Nanjannawar GS, Chopade RV. Grape seed extract: An innovation in remineralization. J Conserv Dent. 2017;20:415-8.

33. Ancuceanu R, Anghel AI, Ionescu C, Hovaneț MV, Cojocaru-Toma M, Dinu M. Clinical Trials with Herbal Products for the Prevention of Dental Caries and Their Quality: A Scoping Study. Biomolecules 2019;9:884.
34. Vieira MS, Nogueira CP, Silva MA, Bauer JR, Maia Filho EM. In vitro evaluation of proximal carious lesions using digital radiographic systems. Scientific World Journal. 2015;63:1508.

35. Weir MD, Chow LC, Xu HH. Remineralization of demineralized enamel via calcium phosphate nanocomposite. J Dent Res 2012; 91:979-84.

36. Silva AP, Gonçalves RS, Borges AF, Bedran-Russo AK, Shinohara MS. Effectiveness of plant-derived proanthocyanidins on demineralization on enamel and dentin under artificial cariogenic challenge. J Appl Oral Sci. 2015 ;23:302-9.

37. Al-Ammar A, Drummond JL, Bedran-Russo AK. The use of collagen cross-linking agents to enhance dentin bond strength. J Biomed Mater Res B Appl Biomater 2009; 91:419-24.

38. Jágr M, Ergang P, Pataridis S, Kolrosová M, Bartoš M, Mikšík I. Proteomic analysis of dentin-enamel junction and adjacent protein-containing enamel matrix layer of healthy human molar teeth. Eur J Oral Sci. 2019;127:112-21.

39. Patri G and Sahu A. Role of Herbal Agents - Tea Tree Oil and Aloe vera as Cavity Disinfectant Adjuncts in Minimally Invasive Dentistry-An In vivo Comparative Study. J Clin Diagn Res. 2017 ; 11:5-9

40. Soulier B. Varnish Entry in: The Grove Dictionary of Musical Instruments, 2d ed., Laurence Libin, Oxford University Press 2014; 5:168- 9

41. Jauhari D, Srivastava N, Rana V, Chandna P. Comparative Evaluation of the Effects of Fluoride Mouthrinse, Herbal Mouthrinse and Oil Pulling on the Caries Activity and Streptococcus mutans Count using Oratest and Dentocult SM Strip Mutans Kit. Int J Clin Pediatr Dent. 2015; 8: 114-8.

42. Marinho VCC, Higgins JPT, Sheiham A, Logan S. Combinations of topical fluoride (toothpastes, mouthrinses, gels, varnishes) versus single topical fluoride for preventing dental caries in children and adolescents (Cochrane Review). In: The Cochrane Library, Issue 1, 2004. Chichester, UK: John Wiley \& Sons, Ltd.

43. Irigoyen-Camacho ME, Luengas-Aguirre MI, AmadorPedraza Y, Amador-Pedraza Y, Zepeda-Zepeda MA, Villanueva-Gutiérrez T. Comparison of varnishes and fluoridated toothpaste for the prevention of dental caries in school children. Rev Salud Publica (Bogota). 2015; 17:801-14.

44. Srinivasan M, Schimmel M, Riesen M, Ilgner A, Wicht MJ, Warncke M. High-fluoride toothpaste: a multicenter randomized controlled trial in adults. Community Dent Oral Epidemiol. 2014; 42: 333- 40. 